\title{
Effect of aging on the magnetic properties of rapidly quenched Nd-rich Nd-Fe alloys
}

\author{
Dennis Wiafe-Akenteng, Vladimir Menushenkov, Igor Shchetinin, Alexander Savchenko \\ National University of Science and Technology «MISiS», Leninskiy pr. 4, Moscow, Russia
}

\begin{abstract}
The $\mathrm{Fe}_{x} \mathrm{Nd}_{100-x}(x=14,28)$ alloys were successfully prepared by melt-spinning. Hysteretic and thermomagnetic properties of the as-melt-spun alloys and short-aged ribbons were investigated. Both ribbons exhibit a soft magnetic behavior at room temperature but at $5 \mathrm{~K}$, the coercive force $\left(\mathrm{H}_{\mathrm{ci}}\right)$ proliferated to $8.6 \mathrm{kOe}$ and $11.7 \mathrm{kOe}$, respectively. Thermomagnetic measurements, Zero Field Cooling (ZFC) and Field Cooling (FC), demonstrated that the rise in magnetization of the ribbons at temperatures lower $34 \mathrm{~K}$ is associated with ferromagnetism of fcc $\mathrm{Nd}-\mathrm{Fe}$ solid solution clusters. Positive effect of aging on the coercivity of the $\mathrm{Fe}_{14} \mathrm{Nd}_{86}$ and $\mathrm{Fe}_{28} \mathrm{Nd}_{72}$ ribbons was observed. At $300 \mathrm{~K}, \mathrm{H}_{\mathrm{ci}}$ of the ribbons upsurge to $2-2.8 \mathrm{kOe}$ after aging at $400-450^{\circ} \mathrm{C}$ for 15 minutes but sharply diminished after aging at temperatures higher than $500^{\circ} \mathrm{C}$. It was suggested that the increase in RT coercivity during aging was as a result of the decomposition of the amorphous phase and formation of the hard magnetic Fe-rich clusters. For both ribbons aged at $500^{\circ} \mathrm{C}$, the magnetic transition at $340 \mathrm{~K}$ was observed to be in relation to the $\mathrm{T}_{\mathrm{C}}$ of the $\mathrm{Nd}_{2} \mathrm{Fe}_{17}$ compound. The appearance of this soft magnetic phase in the microstructure of the aged ribbons was linked with the drastic diminution of the coercivity at that temperature.
\end{abstract}

\section{Introduction}

The interest in the study of the Nd-Fe alloys was renewed during the last decades owing to the significant role Nd-rich intergranular phase play in the development of high coercivity of sintered Nd-Fe-B-based magnets. Usually, a high coercivity in the sintered magnets is obtained after post sintering aging to produce the optimal microstructure. The effect of the intergranular Nd-rich phase on coercivity was divided into two contributions. The first is the effect of the thin layers between the $\mathrm{Nd}_{2} \mathrm{Fe}_{14} \mathrm{~B}$ grains which consists of amorphous $\mathrm{Nd}-\mathrm{Fe}$ phase. These layers act to reduce or remove defects at the $\mathrm{Nd}_{2} \mathrm{Fe}_{14} \mathrm{~B}$ grain surfaces. Secondly, they tend to decouple the $\mathrm{Nd}_{2} \mathrm{Fe}_{14} \mathrm{~B}$ grains with respect to magnetic exchange interactions [1].

The motivation for the study of binary Nd-Fe alloys is the large coercivity of $4.5 \mathrm{kOe}$ of as-cast Nd-rich $\mathrm{Nd}-\mathrm{Fe}$ alloys without any additional processing step. It is considered that the high coercivity is attributed to the $\mathrm{Nd}-\mathrm{Fe}$ phase with high magnetocrystalline anisotropy [2, 3] which forms during solidification of Nd-rich alloys. The as-cast alloys are characterized by the metastable eutectic structure consisting of the mixture of $\mathrm{Nd}$ grains and the amorphous-like $\mathrm{Fe}-\mathrm{Nd}$ regions denoted in literature as " $\mathrm{A}_{1}$ " phase. The HRTEM imaging from the $\mathrm{Fe}-\mathrm{Nd}$ regions reveals that $\mathrm{A}_{1}$ phase is composed of nanocrystals embedded in an amorphous matrix [4-7]. Unfortunately, the components of $\mathrm{A}_{1}$ regions cannot be identified because of its very fine size.
The coercivity of as-melt-spun Nd-rich alloys is low at room temperature (RT) but increases with decreasing temperature. The microstructure of as-melt-spun Nd-rich alloys consists of an amorphous-like region composed of nanocrystals of unknown phase embedded in an amorphous matrix [6,7]. It is, therefore, expected that aging may lead to additional decomposition of the amorphous phase and formation of the microstructure similar to the one responsible for the high coercivity in as-cast Nd-rich alloys.

In this work, the effect of aging on the magnetic properties - hysteresis loops, thermomagnetic ZFC-FC dependences of $\mathrm{Fe}_{\mathrm{x}} \mathrm{Nd}_{100-\mathrm{x}}(\mathrm{x}=14,28)$ as-melt-spun alloys and polycrystalline $\mathrm{Nd}$ - in a temperature range of 5-300 K were investigated.

\section{Experimental}

Two batches of samples $-\mathrm{Fe}_{14} \mathrm{Nd}_{86}$ and $\mathrm{Fe}_{28} \mathrm{Nd}_{72}$ were prepared from starting materials of high purity elements, iron $(99.95 \%)$ and neodymium (99.9\%). The samples were induction melted and casted under argon atmosphere. The ingots were re-melted and quenched by melt-spinning with a copper-wheel speed of approximately $30 \mathrm{~ms}^{-1}$. The aging of the ribbons was performed in vacuum furnace at temperatures ranging from $300-650^{\circ} \mathrm{C}$ for 15 minutes. Magnetic measurements at temperatures $5 \mathrm{~K}$ and $300 \mathrm{~K}$ were performed using a Quantum Design PPMS EverCool-II

Corresponding author: nanaortchere1@gmail.com 
magnetometer in the magnetizing field of $90 \mathrm{kOe}$. The temperature dependence of magnetization (M) on ZFC and $\mathrm{FC}$ for the aged ribbons were measured in an operating field of $\mathrm{H}=0.5 \mathrm{~T}$ over a wide temperature range $(5-300 \mathrm{~K})$. The specimens were prepared in the form of thin disc from the mixture of the ribbon fragments with epoxy. The error bar of $\mathrm{H}_{\mathrm{ci}}$ values at repeated measurements was less than $3 \%$.

\section{Results and discussion}

Hysteresis loops of the $\mathrm{Fe}_{x} \mathrm{Nd}_{100-x}(x=14$ and 28) asmelt-spun ribbons measured at $300 \mathrm{~K}$ and $5 \mathrm{~K}$ are shown in Figure 1. At $300 \mathrm{~K}$, the hysteresis loops of the ribbons $\mathrm{x}=14,28$ showed a soft magnetic behavior with low magnetization and $\mathrm{H}_{\mathrm{ci}}-75$ and 15 Oe respectively. However, both samples displayed a hard magnetic behavior at $5 \mathrm{~K}$ with an upsurge in coercivity, $8.6 \mathrm{kOe}$ and $11.7 \mathrm{kOe}$ respectively. Maximum value of magnetization in the field of $90 \mathrm{kOe}$ was recorded at $5 \mathrm{~K}, 4$ times as high as the value measured at $300 \mathrm{~K}$. It should be noted that saturation of the hysteresis loops was not achieved even in magnetic field of $90 \mathrm{kOe}$.

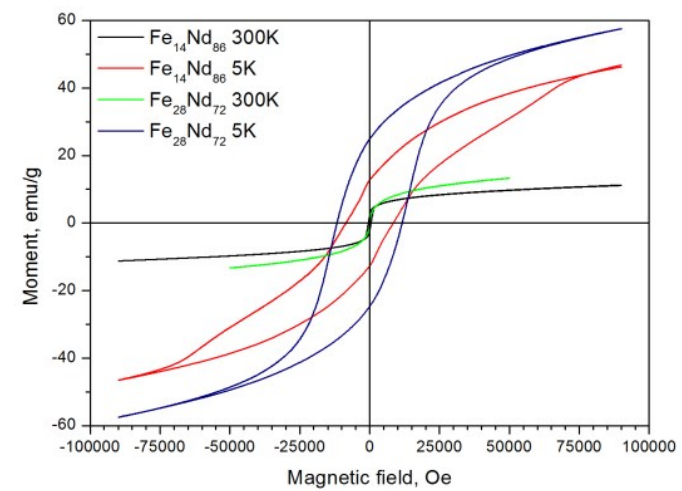

Figure 1. Hysteresis loops of the $\mathrm{Fe}_{14} \mathrm{Nd}_{86}$ and $\mathrm{Fe}_{28} \mathrm{Nd}_{72}$ as-melt-spun ribbons measured at $5 \mathrm{~K}$ and $300 \mathrm{~K}$

Figure $2 \mathrm{a}$ shows a rise in coercivity of $\mathrm{Fe}_{14} \mathrm{Nd}_{86}$ and $\mathrm{Fe}_{28} \mathrm{Nd}_{72}$ ribbons when temperature decreases from $300 \mathrm{~K}$ to $5 \mathrm{~K}$. The temperature dependence of coercivity show a linear relationship between $H_{c}^{1 / 2}$ and $T^{2 / 3}$ in the temperature range $25-200 \mathrm{~K}$ (Figure $2 \mathrm{~b}$ ).
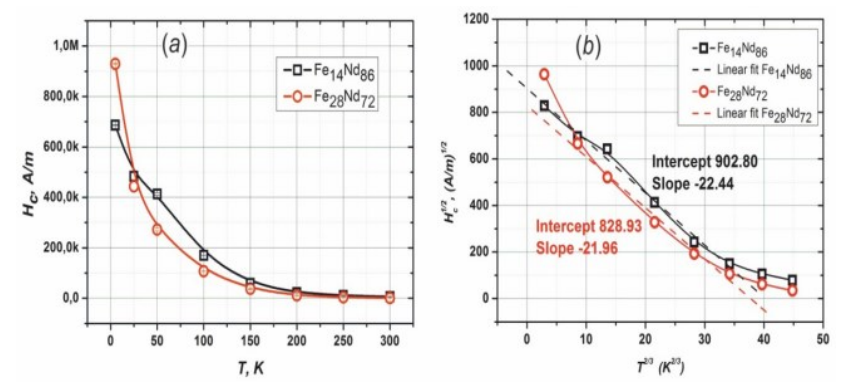

Figure 2. Temperature dependences of $\mathrm{H}_{\mathrm{c}}(\mathrm{T})$ (a) and dependences of $H_{C}{ }^{1 / 2}\left(T^{2 / 3}\right)$ (b) for $\mathrm{Fe}_{14} \mathrm{Nd}_{86}$ and $\mathrm{Fe}_{28} \mathrm{Nd}_{72}$ ribbons over the range $5-300 \mathrm{~K}$

These data demonstrate an agreement with strong pinning model of domain walls, proposed by Gaunt [8]. According to $[6,7]$, the coercivity of the as-melt-spun $\mathrm{Fe}_{14} \mathrm{Nd}_{86}$ and $\mathrm{Fe}_{28} \mathrm{Nd}_{72}$ ribbons at lower temperatures is associated with a domain wall pinning on the Nd-rich nanocrystals embedded in an amorphous-like matrix phase which are observed in the ribbons microstructure.

For the interpretation of the temperature dependence of coercivity, temperature dependences of magnetization in the range 5-300 $\mathrm{K}$ were made to reveal the possible magnetic transitions. ZFC and FC curves (Figure 3) displays the magnetization behavior of the as-melt-spun $\mathrm{Fe}_{14} \mathrm{Nd}_{86}$ ribbon and polycrystalline $\mathrm{Nd}$ in operating field of $\mathrm{H}=0.5 \mathrm{kOe}$ over a temperature range $5-300 \mathrm{~K}$. Comparing the $\mathrm{ZFC}$ and $\mathrm{FC}$ curves for $\mathrm{Nd}$ and $\mathrm{Fe}_{14} \mathrm{Nd}_{86}$ ribbon at temperatures lower than $50 \mathrm{~K}$ shows the magnetic transitions at $\approx 9 \mathrm{~K}, \approx 17 \mathrm{~K}$ and $\approx 34 \mathrm{~K}$ in both $\mathrm{Nd}$ and ribbon. The observation of these magnetic transitions suggests the presence of several magnetic phases in microstructure of both the crystalline $\mathrm{Nd}$ and $\mathrm{Fe}_{14} \mathrm{Nd}_{86}$ ribbon. According to [9], the first two transitions correspond to antiferromagnetic ordering temperature of the $d h c p \mathrm{Nd}$ (the onset of ordering on cubic sites). This suggests that the ferromagnetic transition at $34 \mathrm{~K}$ is related to the metastable $f c c$ allotrope of $\mathrm{Nd}$ or $\mathrm{Nd}-\mathrm{Fe}$ solid solution (Nd-based nanocrystals) [6,7]. Hence, the possible reason for an upsurge in the magnetization at high fields at temperatures lower than $34 \mathrm{~K}$ is the presence of $f c c \mathrm{Nd}$ and Nd-based phases.

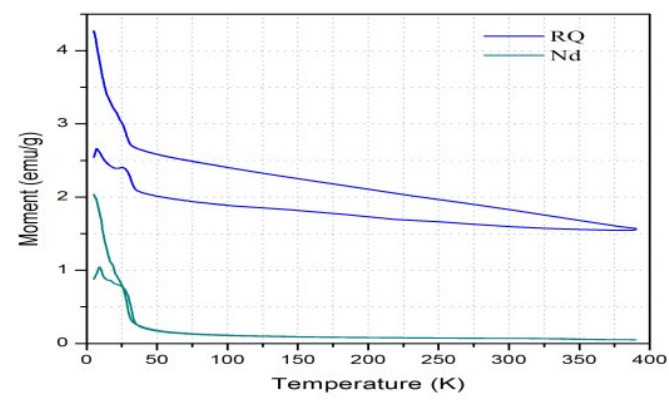

Figure 3. $\mathrm{ZFC}$ and $\mathrm{FC}$ thermomagnetic curves of the $\mathrm{Fe}_{14} \mathrm{Nd}_{86}$ ribbon (RQ) and polycrystalline $\mathrm{Nd}$

The paramagnetic susceptibility of the $f c c \mathrm{Nd}$ and $\mathrm{Nd}-\mathrm{Fe}$ solid solution resulted in unsaturated magnetization curves for the $\mathrm{Fe}_{14} \mathrm{Nd}_{86}$ ribbon at temperatures above $34 \mathrm{~K}$. But the fact that saturation of the hysteresis loops is not achieved at $5 \mathrm{~K}$ shows the presence of high magnetocrystalline anisotropy of $\mathrm{Nd}$ which connotes magnetic moments remain noncollinear down to $5 \mathrm{~K}$. For this reason, the random-anisotropy model [10] of the Fe-contained clusters may be used to explain the magnetic properties of as-melt-spun ribbons. In the zero field, the magnetization moments of the Nd-Fe clusters are directed along the easy axes which have random orientation. An increasing magnetic field overcomes the anisotropy energy and aligns the magnetization moments of the clusters towards the field direction.

It was observed that a short aging of the $\mathrm{Fe}_{14} \mathrm{Nd}_{86}$ and $\mathrm{Fe}_{28} \mathrm{Nd}_{72}$ ribbons at temperatures lower than the eutectic temperature in $\mathrm{Fe}-\mathrm{Nd}$ system $\left(685^{\circ} \mathrm{C}\right)$ increased the coercivity. It might be as a result of transforming their microstructure which was composed of Nd-based nanocrystals and residual amorphous phase. It could also 
be caused by decomposition of the amorphous phase and precipitation of the Fe-rich clusters with high magnetocrystalline anisotropy which increased the coercivity. On the other hand, the precipitation of the soft magnetic $\mathrm{Fe}_{2} \mathrm{Nd}_{17}$ clusters resulted in lessening the coercivity. Secondly, the increase of the size of Nd-rich nanocrystals during aging may have resulted in the nanocrystals losing the role as the domain walls pinning centers.

The hysteresis loops of the $\mathrm{Fe}_{14} \mathrm{Nd}_{86}$ and $\mathrm{Fe}_{28} \mathrm{Nd}_{72}$ ribbons measured at $300 \mathrm{~K}$ and $5 \mathrm{~K}$ after aging at $300-$ $600^{\circ} \mathrm{C}$ for 15 minutes are shown in Figures 4 and 5 respectively. The temperature dependences of coercivity for the $\mathrm{Fe}_{14} \mathrm{Nd}_{86}$ and $\mathrm{Fe}_{28} \mathrm{Nd}_{72}$ ribbons over the aging temperature range $300-600^{\circ} \mathrm{C}$ are shown in Figure 6. Maximum values of coercivity, $3.1 \mathrm{kOe}$ and $2.6 \mathrm{kOe}$, were received after aging at $400-450^{\circ} \mathrm{C}$ for the ribbons $\mathrm{x}=14,28$ respectively measured at $300 \mathrm{~K}$. These values of coercivity is only slightly less than the coercivity of as-cast Nd-rich Fe-Nd alloys, $\mathrm{H}_{\mathrm{ci}}=4-4.5$ kOe $[2,3]$. Aging at temperatures higher than $450^{\circ} \mathrm{C}$ recorded a reduction in coercivity for the $\mathrm{Fe}_{14} \mathrm{Nd}_{86}$ and $\mathrm{Fe}_{28} \mathrm{Nd}_{72}$ ribbons.
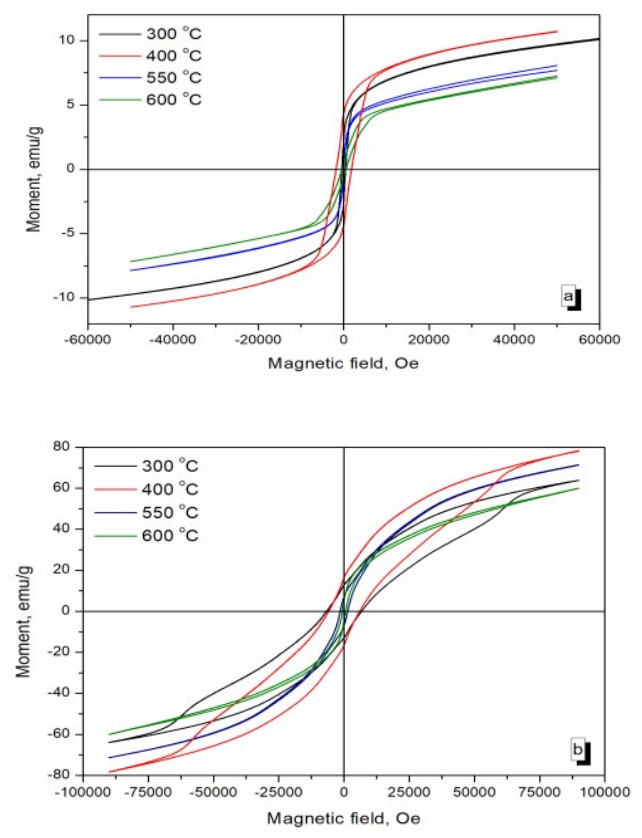

Figure 4. Hysteresis loops of the $\mathrm{Fe}_{14} \mathrm{Nd}_{86}$ ribbons after aging at $300-600^{\circ} \mathrm{C}$ for $15 \mathrm{~min}$ measured at $5 \mathrm{~K}$ (a) and $300 \mathrm{~K}(\mathrm{~b})$

As seen in Figure $6 \mathrm{a}$, at $5 \mathrm{~K}$, the coercivity of as-meltspun $\mathrm{Fe}_{14} \mathrm{Nd}_{86}$ and $\mathrm{Fe}_{28} \mathrm{Nd}_{72}$ ribbons (8.6 kOe and 11.7 $\mathrm{kOe}$, respectively), slightly reduced after aging in the temperature range of $300-450^{\circ} \mathrm{C}$ and decreased drastically after aging at $500^{\circ} \mathrm{C}$ and higher temperatures. At $300 \mathrm{~K}$, the coercivity of as-melt-spun ribbons $\mathrm{Fe}_{14} \mathrm{Nd}_{86}$ and $\mathrm{Fe}_{28} \mathrm{Nd}_{72}$ (75 and 15 Oe, respectively) rose to $2-2.8 \mathrm{kOe}$ after aging at $400-450^{\circ} \mathrm{C}$. A sharp drop was observed after aging at temperatures higher than $500^{\circ} \mathrm{C}$.
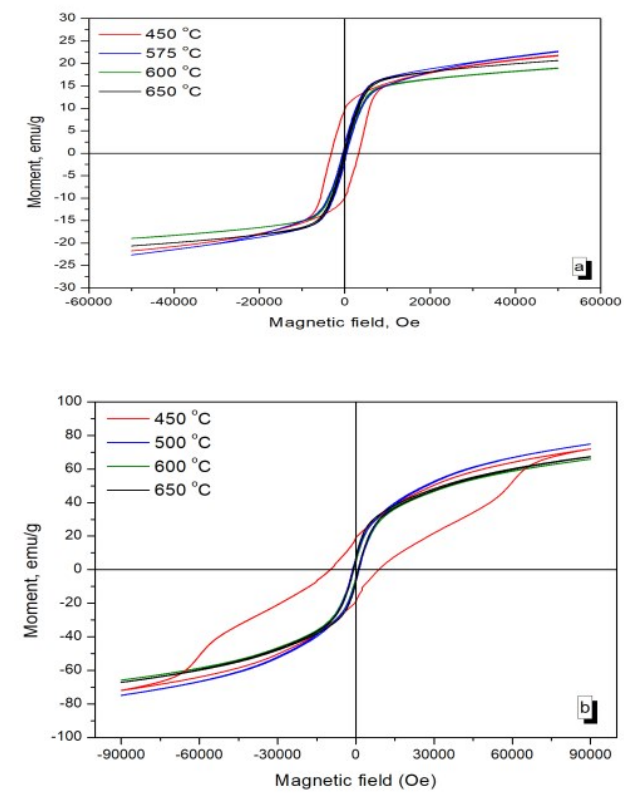

Figure 5. Hysteresis loops of the $\mathrm{Fe}_{28} \mathrm{Nd}_{72}$ ribbons after aging at $300-600 \mathrm{C}$ for $15 \mathrm{~min}$ measured at $5 \mathrm{~K}$ (a) and $300 \mathrm{~K}$ (b)
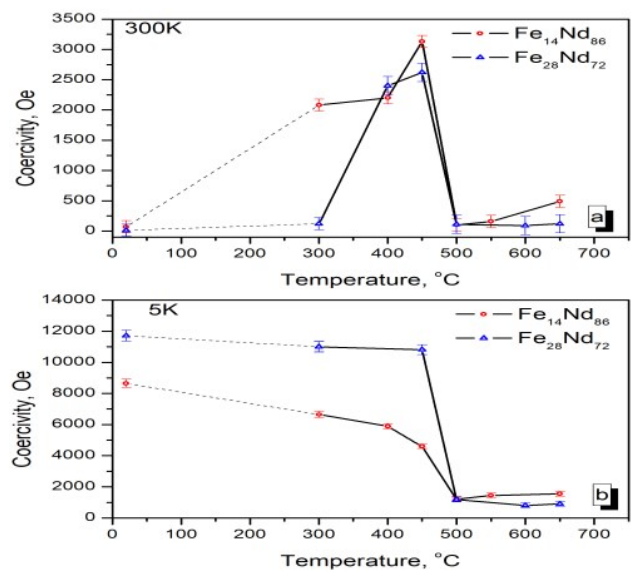

Figure 6. Dependences of $\mathrm{H}_{\mathrm{c}}$ versus the aging temperature for the ribbon $\mathrm{Fe}_{14} \mathrm{Nd}_{86}$ (a) and $\mathrm{Fe}_{28} \mathrm{Nd}_{72}$ (b) measured at $5 \mathrm{~K}$ and $300 \mathrm{~K}$ after aging at $300-650 \mathrm{C}$ for $15 \mathrm{~min}$

For the interpretation of this data, it was suggested that the main reason for an increase in RT coercivity after short aging at $400-450^{\circ} \mathrm{C}$ is decomposition of the amorphous phase and formation of the Fe-rich clusters of the hard magnetic phase like that in as-cast Nd-Fe alloy. The low level of coercivity of the aged ribbons at $300 \mathrm{~K}$ $(1.8-2 \mathrm{kOe})$ in comparison with $\mathrm{H}_{\mathrm{ci}}$ of the as-cast alloy $(4.5 \mathrm{kOe})$ can be explained as due to the non-optimal composition or size of the Fe-rich clusters and a coarsening of the Nd-rich nanocrystals during aging hence decreasing the domain wall pinning.

Figure 7 shows the ZFC and FC thermomagnetic curves of the ribbons $\mathrm{Fe}_{14} \mathrm{Nd}_{86}$ (a) and $\mathrm{Fe}_{28} \mathrm{Nd}_{72}$ (b) after aging at $300-650 \mathrm{C}$ for 15 minutes. The comparison of the ZFC and FC curves of $\mathrm{Fe}_{14} \mathrm{Nd}_{86}$ and $\mathrm{Fe}_{28} \mathrm{Nd}_{72}$ ribbons after melt spinning and after aging in Figures 3 and 7 
shows that aging has no effect on the temperature of the bends on the $\mathrm{M}(\mathrm{T})$ curves at temperatures lower than $50 \mathrm{~K}$. Hence, the composition of $\mathrm{Nd}$ or Nd-based solid solution in these ribbons remains unchanged.

As demonstrated in Figure 7, the temperature dependences of magnetization (FC) for the $\mathrm{Fe}_{14} \mathrm{Nd}_{86}$ and $\mathrm{Fe}_{28} \mathrm{Nd}_{72}$ ribbons aged at temperatures $300-450^{\circ} \mathrm{C}$ shows that magnetic transition $\left(\mathrm{T}_{\mathrm{C}}\right)$ takes place at temperatures higher than $500 \mathrm{~K}$. But for both ribbons aged at $500^{\circ} \mathrm{C}$, the magnetic transition was observed at $330-340 \mathrm{~K}$ which is close to the $\mathrm{T}_{\mathrm{C}}$ of the $\mathrm{Nd}_{2} \mathrm{Fe}_{17}$ compound $(335 \mathrm{~K})$. The appearance of this soft magnetic phase in the microstructure of the aged ribbons resulted in drastic decrease in the coercivity.
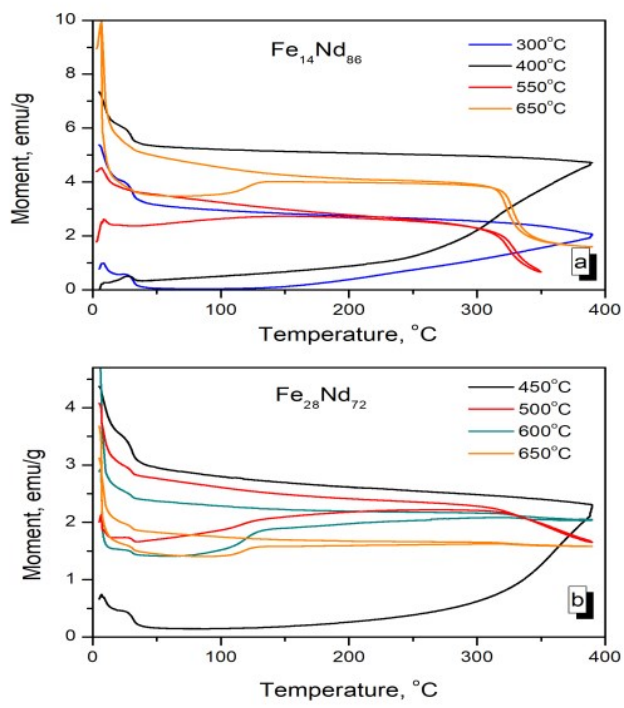

Figure 7. Zero-field cooling (ZFC) and field cooling (FC) thermomagnetic curves of the ribbon $\mathrm{Fe}_{14} \mathrm{Nd}_{86}$ (a) and $\mathrm{Fe}_{28} \mathrm{Nd}_{72}$ (b) after aging at $450-650 \mathrm{C}$ for $15 \mathrm{~min}$

Based on the obtained data, it can be discussed that the possible mechanism of the intergranular phase has an influence on the $\mathrm{H}_{\mathrm{ci}}$ of sintered magnets during postsintering aging. Usually, in sintered magnets the Nd-rich intergranular phase is an amorphous region similar to the amorphous-like phase in as-melt-spun Nd-rich ribbons. It may be assumed that the post-sintering aging of the ribbons led to the decomposition of the intergranular amorphous phase and appearance of the Fe-Nd clusters, similar to the clusters in as-melt-spun ribbons that resulted in a rise in the $\mathrm{H}_{\mathrm{ci}}$ of aged magnets.

\section{Conclusion}

Hysteretic and thermomagnetic properties of the $\mathrm{Fe}_{14} \mathrm{Nd}_{86}$ and $\mathrm{Fe}_{28} \mathrm{Nd}_{72}$ as-melt-spun alloys and short aged ribbons were investigated. The present study showed that as-melt-spun ribbons exhibit a soft magnetic behavior at room temperature but with decreasing temperature from 300 to $5 \mathrm{~K}, \mathrm{H}_{\mathrm{ci}}$ proliferated up to 8.6 $\mathrm{kOe}$ and $11.7 \mathrm{kOe}$, respectively. The increase in $\mathrm{H}_{\mathrm{ci}}$ can be associated with a domain wall pinning on the $\mathrm{Nd}$-rich nanocrystals embedded in an amorphous-like matrix which were observed in the microstructure of the ribbons.

Thermomagnetic measurements (ZFC and FC) for the as-melt-spun $\mathrm{Fe}_{14} \mathrm{Nd}_{86}$ and $\mathrm{Fe}_{28} \mathrm{Nd}_{72}$ ribbons show magnetic transitions at 9,17 and $\approx 34 \mathrm{~K}$. The first two transitions, 9 and $17 \mathrm{~K}$, originated from $d h c p \mathrm{Nd}$ and the third transition is associated with ferromagnetism of $f_{c c}$ $\mathrm{Nd}-\mathrm{Fe}$ solid solution which resulted in an increase of the magnetization of the ribbons at temperature lower than $34 \mathrm{~K}$.

The positive effect of aging on the $\mathrm{H}_{\mathrm{ci}}$ of the as-meltspun $\mathrm{Fe}_{14} \mathrm{Nd}_{86}$ and $\mathrm{Fe}_{28} \mathrm{Nd}_{72}$ ribbons was observed. At $300 \mathrm{~K}$, the $\mathrm{H}_{\mathrm{ci}}$ of the as-melt-spun ribbons (75 and 15 Oe, respectively), escalated to $2-2.8 \mathrm{kOe}$ after aging at $400-450^{\circ} \mathrm{C}$ but sharply declined after aging at temperatures higher than $500^{\circ} \mathrm{C}$. It was suggested that the main reason for the rise in $\mathrm{RT}_{\mathrm{ci}}$ during aging is the decomposition of the amorphous phase and formation of the hard magnetic Fe-rich clusters. For both ribbons aged at $500^{\circ} \mathrm{C}$, magnetic transition was observed at $340 \mathrm{~K}$, closer to the $\mathrm{T}_{\mathrm{C}}$ of the $\mathrm{Nd}_{2} \mathrm{Fe}_{17}$ compound $\left(\mathrm{T}_{\mathrm{C}}=335 \mathrm{~K}\right)$. The appearance of this soft magnetic phase in the microstructure of the aged ribbons resulted in $\mathrm{H}_{\mathrm{ci}}$ reducing drastically.

Further studies must be mainly directed to structural analysis of the aged samples to help clarify the effect of aging on its magnetic properties.

Acknowledgement. This work was supported by the Ministry of Education and Science of the Russian Federation (agreement no. 14.587.21.0028, a unique no. RFMEFI58716X0028).

\section{References}

[1] T.G. Woodcock, Y. Zhang, G. Hrkac, G. Ciuta, N.M. Dempsey, T. Schrefl, O. Gutfleisch, D. Givord. Scripta Materialia 67 (2012) 536.

[2] Drozzina V, Janus R. Nature, 1935, 135, 36.

[3] J.J. Croat, Appl. Phys. Lett., 1981, 39, 357.

[4] V. P. Menushenkov, A. S. Lileev, M. A. Oreshkin, S. A. Zhuravlev, J. Magn. Magn. Mater., 1999, 203, 149.

[5] Kumar, J. Eckert, S. Roth, W. Loser, L. Schultz, S. Ram. Acta Materialia, 51 (2003) 229.

[6] Menushenkov, V. P., Shchetinin, I. V., Gorshenkov, M. V., Savchenko, A. G., \& Ketov, S. V. (2016). IEEE Magnetics Letters, 7, 1-4.

[7] V.P. Menushenkov, I.V. Shchetinin, M.V. Gorshenkov, A.G. Savchenko, S.V. Ketov, Proc. of the 24-th Int. Workshop on Rare-Earth and Future Permanent Magnets and their Applications (REPM 2016), 2016, Darmstadt, Germany.

[8] P. Gaunt. Philos. Mag. B, 1983, 48, 261.

[9] E. Bucher, C. W. Chu, J. P. Maita, K. Andres, A. S. Cooper, E. Buehler, and K. Nassau, Phys. Rev. Lett., 1969, 22, 1260.

[10] R. Ribas, B. Dieny, B. Barbara, A. Labrata, J. Phys. Condens. Matter, 1995, 7, 3301. 